\title{
Research Article \\ DEVELOPMENT OF DUS DESCRIPTOR FOR CASUARINA GENETIC RESOURCES
}

\section{PARTHIBAN K.T. *, KANAGARAJ N., PALANIKUMARAN B. AND KRISHNAKUMAR N.}

Department of Agroforestry, Forest College and Research Institute, Mettupalayam, 641301, Tamil Nadu Agricultural University, Coimbatore, Tamil Nadu 641003, India *Corresponding Author: Email- ktparthi2001@gmail.com, kanagaforester007@yahoo.co.in

Received: February 09, 2018; Revised: February 16, 2018; Accepted: February 18, 2018; Published: February 28, 2018

Abstract- The study was taken up with the objective to develop and document descriptors for casuarina genetic resource, which enables the identification of varieties for varietal registration. Descriptors were developed of casuarina genetic resources after surveying the 17 clones Based on the morphological character. Among the clone studied, 15 descriptors were developed and documented, which consist of 7 quantitative characters and 8 qualitative cha racters.

Keywords: Descriptors, Casuarina, DUS, Genetic resources

Citation: Parthiban K.T., et al., (2018) Development of Dus Descriptor for Casuarina Genetic Resources. International Journal of Genetics, ISSN: 0975- 2862 \& E-ISSN: 0975-9158, Volume 10, Issue 1, pp.-333-338. DOI: http://dx.doi.org/10.9735/0975-2862.10.1.333-338

Copyright: Copyright@2018 Parthiban K.T., et al., This is an open-access article distributed under the terms of the Creative Commons Attribution License, which permits unrestricted use, distribution and reproduction in any medium, provided the original author and source are credited.

Academic Editor / Reviewer: Dr Manish Sachan

\section{Introduction}

Casuarina is a nitrogen-fixing tree. They are distributed in Australia, Southern Asia, Pacific Islands, tropical and subtropical regions. In these regions, Casuarina is used for landscaping, timber, dye, pulp, tannin, wood fuel production, soil stabilization, reforestation of marginal ecosystems and land fertilization [1]. Because It Is Salt and Drought Tolerant, And Fast Growing, Casuarina Also Used As Windbreaks And Sand-Shifting Control In Many Parts Of The World Due to its importance, there is a major effort underway focused on selecting and planting elite clones of Casuarina in India, but the efficiency of this approach requires the genetic characterization of available genetic resources [2].

Plant genetic resources normally distinguish by morphological, phonological, biochemical components with DUS. Descriptors are defined as an attribute, characteristic are measurable feature used in a germ plasma bank accession [3]. The use of list of well-defined rigorously tested descriptor greatly simply the operation associated with data registration with regard to the characterization and evaluation of cultivars. Elaboration of list of a descriptor a dynamic, open process and standardization of a descriptors is essential so that the characterization is universal value. However, it is hoped that the descriptor will serve as a reference to characterize the available diversity to a large extent. Hence studies were initiated to develop DUS (Distinctiveness, Uniformity and Stability) descriptors as per the guidelines of PPV and FRA for casuarina genetic resources maintained at Forest College and Research Institute, Tamil Nadu, India.

\section{Materials and Methods}

The present study was carried out using the already established field trial at Forest College and Research Institute, Mettupalayam $\left(11019^{\prime} \mathrm{N} ; 76056{ }^{\prime} \mathrm{E} ; 300\right.$ MSL), Tamil Nadu Agricultural University, India. The site enjoys an annual rainfall of $830 \mathrm{~mm}$. The mean maximum and minimum temperature are $32.2^{\circ} \mathrm{C}$ and $23.2^{\circ} \mathrm{C}$ respectively.

\section{Experimental Layout}

The site was laid out randomized block design (RBD) with 17 casuarina clones as treatments and three replications for each treatment with spacing of $1.5 \mathrm{M} \times 1.5 \mathrm{M}$

\section{Data Collection and Analysis:}

Data were collected on morphological (both quantitative and qualitative) characters using a character's descriptors. Type of assessment of characteristics was as follows [4].

MG: Measurement by a single character of a plant

VG: Visual assessment by a single observation of a group of plants or parts of plants.

VS: Visual assessment by observation of individual plants or parts of plants

\section{Descriptors}

The requirement of Distinctiveness, uniformity and stability were assessed on the basis of descriptors. The descriptors are a feature of whole plant or part of plant. These descriptors were developed based on the phonotypic assessment of 17 casuarina genetic resources. The observed and measured properties determined in the DUS testing procedure for a new variety shall be qualitative and quantitative. All extensive preliminary field survey was conducted during 2016-17 to identify and document clones with distinct uniform and stable morphological character in casuarina clones.

The selection was made on phenotypic assessment of a character with distinctiveness viz., crown, bark, Branchlet, Lenticel. A total 17 casuarina clones were focus on DUS characterization using morphological descriptor. A step involved and list of character chosen for descriptor development are as follows. Identification and screening of characters with distinctness based on the existing tree information followed by examination of screened characters for its uniformity and stability. Examination of specific time i.e. at the time the most relevant characters can be assessed. Photographic documentation of visually assessed characters Branchlet Colour, Lenticel shape, lenticel grouping, branching pattern, branch angle, bark colour, bark texture, crown shape was done on site. Measurable characters viz., branchlets length, branchlet thickness, branchlet leaves per node, Branchlet Internode length, lenticel size, lenticels density, branch thickness.

\section{Results and Discussion}

Descriptors were developed of casuarina genetic resources after surveying the 17 
clones. Among the clone studied, 15 descriptors were developed and documented, which consist of 7 quantitative characters and 8 qualitative characters. Among the characters, five descriptors were developed for casuarina branch lets, four descriptors for lenticels, three descriptors for branches, two descriptors for bark and one descriptors for crown have been used. The data from identified existing clones of casuarina revealed greater variability in branchlet characters are furnished in [Table-1].

\begin{tabular}{|c|c|c|c|c|}
\hline \multicolumn{5}{|c|}{ Table-1 DUS traits for Crown and Branchlet character } \\
\hline $\begin{array}{l}\text { S. } \\
\text { No. }\end{array}$ & Characteristic & State & Clones & $\begin{array}{c}\text { Type of } \\
\text { assessment }\end{array}$ \\
\hline 1. & Crown shape & Lanceolate & $\begin{array}{l}\text { CJ 19240-01,CJ 19240-02, } \\
\text { CJ 19240-03,CJ 19240-06, } \\
\text { CJ 19553-07,CJ 19553-08, } \\
\text { CJ 19553-09, CJ 19553-11, } \\
\text { CJ 19553-12,CJ 19553-13, } \\
\text { CJH-01-14,CJH-02, } \\
\text { CJ 19553 SS }\end{array}$ & \multirow[t]{2}{*}{ VS } \\
\hline & & Conical & $\begin{array}{l}\text { CJ 19240-04, CJ 19240-05, CJ 19553-07, CJ 19553-10 } \\
\text { and MTP2 (Check) }\end{array}$ & \\
\hline \multirow[t]{2}{*}{2.} & \multirow[t]{2}{*}{ Branchlet Colour } & Dark green & $\begin{array}{c}\text { CJ 19240-01, CJ 19240-03, CJ 19240-05, CJ 19553-09, CJ } \\
\text { 19553-11, CJ 19553-13, MTP2 and CJ 19553 SS }\end{array}$ & \multirow[b]{2}{*}{ VG } \\
\hline & & yellowish green & $\begin{array}{c}\text { CJ 19240-02, CJ 19240-04, CJ 19240-06, CJ 19240-07, CJ } \\
\text { 19240-08, CJ 19553-10, CJ 19553-12, CJH-01-14 and } \\
\text { CJH-01-14 }\end{array}$ & \\
\hline \multirow[t]{3}{*}{3.} & \multirow[t]{3}{*}{ Branchlet Length } & $\begin{array}{c}\text { Short } \\
(<15 \mathrm{~cm})\end{array}$ & $\begin{array}{l}\text { CJ 19240-02, CJ 19553-08, CJ 19553-09, CJ 19553-11, CJ } \\
\text { 19553-12 and MTP2 }\end{array}$ & \multirow{3}{*}{ MG } \\
\hline & & $\begin{array}{l}\text { Intermediate } \\
(15-25 \mathrm{~cm})\end{array}$ & $\begin{array}{c}\text { CJ 19240-04, CJ 19553-07, CJ 19553-10, CJ 19553-13, } \\
\text { CJH-01-14, CJH-02, } \\
\text { CJ 19553 SS }\end{array}$ & \\
\hline & & $\begin{array}{c}\text { Long } \\
(>25 \mathrm{~cm})\end{array}$ & CJ 19240-01, CJ 19240-03, CJ 19240-05 and CJ 19240-06 & \\
\hline \multirow[t]{4}{*}{4.} & \multirow[t]{4}{*}{$\begin{array}{l}\text { Branchlet } \\
\text { thickness }\end{array}$} & $\begin{array}{c}\text { Thin } \\
(<0.3 \mathrm{~mm})\end{array}$ & MTP2 & \multirow{4}{*}{ MG } \\
\hline & & $\begin{array}{l}\text { Intermediate } \\
(0.3-0.6 \mathrm{~mm})\end{array}$ & CJ 19240-02 and CJ 19553-12 & \\
\hline & & $\begin{array}{l}\text { Thick } \\
(>0.6 \mathrm{~mm})\end{array}$ & $\begin{array}{l}\text { CJ 19240-01, CJ 19240-03, CJ 19240-04,CJ 19240-05, } \\
\text { CJ 19240-06,CJ 19553-07, } \\
\text { CJ 19553-08,CJ 19553-09, } \\
\text { CJ 19553-10,CJ 19553-11, } \\
\text { CJ 19553-13,CJH-01-14, } \\
\text { CJH-02, CJ 19553 SS }\end{array}$ & \\
\hline & & $\begin{array}{c}\text { Thin } \\
(<0.3 \mathrm{~mm})\end{array}$ & MTP2 & \\
\hline \multirow[t]{3}{*}{5.} & \multirow[t]{3}{*}{$\begin{array}{c}\text { Branchlet: } \\
\text { Leaves per node }\end{array}$} & $\begin{array}{l}\text { Less than } 6 \\
\text { Leaves }\end{array}$ & CJ 19553-07 & \multirow[b]{3}{*}{ VG } \\
\hline & & 10 leaves & CJ 19240-03, CJ 19240-04, CJ 19553-09 and CJ 19553 SS & \\
\hline & & $\begin{array}{l}\text { More than } 10 \\
\text { Leaves }\end{array}$ & $\begin{array}{c}\text { CJ 19240-01, CJ 19240-02, CJ 19240-05, CJ 19240-06, CJ } \\
\text { 19553-08,CJ 19553-10, CJ 19553-11,19553-12, } \\
\text { CJ 19553-13,CJH-01-14, } \\
\text { CJH-02. MTP2 }\end{array}$ & \\
\hline \multirow[t]{3}{*}{6.} & \multirow[t]{3}{*}{$\begin{array}{c}\text { Branchlet: } \\
\text { Internode length }\end{array}$} & $\begin{array}{c}\text { Short } \\
(<5 \mathrm{~mm})\end{array}$ & $\begin{array}{c}\text { CJ 19240-01, CJ 19240-03, CJ 19240-05, CJ 19553-07, CJ } \\
\text { 19553-08, CJ 19553-11, CJ 19553-12 and CJ 19553 SS }\end{array}$ & \multirow{3}{*}{ VG } \\
\hline & & $\begin{array}{l}\text { Medium } \\
(5-8 \mathrm{~mm})\end{array}$ & $\begin{array}{c}\text { CJ 19240-02, CJ 19240-06, CJ 19553-10, CJ 19553-13, } \\
\text { CJH-01-14, CJH-02, } \\
\text { MTP2 (Check) }\end{array}$ & \\
\hline & & Long $(>8 \mathrm{~mm})$ & $\begin{array}{l}\text { CJ 19240-04 and } \\
\text { CJ 19553-09 }\end{array}$ & \\
\hline
\end{tabular}

\section{DUS traits for Crown and Branchlet character}

The predominant crown shape identified as lanceolate followed by conical. Conical Type Exhibited Distinctness Throught out the Casuarina Plantation. The casuarina genetic resources exhibited distinct two different branchletcolour which are dark green and yellowish green. Out of 17 clones, nine clones viz., CJ 19240 02, CJ 19240-04, CJ 19240-06, CJ 19240-07, CJ 19240-08, CJ 19553-10, CJ 19553-12 and CJH-01-14 with the yellowish green colour other eight clones grouped in the dark green branchlets. The length of the breanchlet is categorized in three groups viz., short $(<15 \mathrm{~cm})$, intermediate $(15-25 \mathrm{~cm})$ and long $(>25 \mathrm{~cm})$. Four clones viz., CJ 19240-01, CJ 19240-03, CJ 19240-05 and CJ 19240-06 grouped under the category of long branchlet and rest of the clones are grouped in short and intermediate branchlet length. Based on thickness of the branchlet, casuarina clones are classified into thin $(<0.3 \mathrm{~mm})$, intermediate and thick $(>0.6$ $\mathrm{mm}$ ). The clone MTP2 grouped in thin category while two clones viz., CJ 19240-02 and CJ 19553-12 grouped in intermediate category and the rest of the fourteen clones grouped in thick category. The casuarina clones have been characterized for Branchlet leaves per node which exhibit three different types which are follows; $<6$ leaves per node, 10 leaves per node and >10 leaves per node. Only one clone viz., CJ 19553-07 exhibited less than 6 leaves per node. The remaining sixteen clones grouped in the category of 10 leaves per node and more than 10 leaves per node. According to Branchlet internode length, eight clones viz., $\mathrm{CJ}$ 19240-01, CJ 19240-03, CJ 19240-05, CJ 19553-07, CJ 19553-08, CJ 19553-11, CJ 19553-12 and CJ 19553 SS grouped under short internode length. Remaining nine clones are grouped under the category of medium and long internode length. Our results agree with other studies showing heterogeneity is major sources of variations in crown shape also have been reported in Pongamia pinnata [5]. Similar descriptor study was showing significant morphological variations in branchlet colour, branch let thickness and branch let leaves per node of casuarinas [6]. 
Parthiban K.T., Kanagaran J., Palanikumaran B. and Krishnakumar N.

\begin{tabular}{|c|c|c|c|c|}
\hline \multicolumn{5}{|c|}{ Table-2 DUS traits for Lenticels } \\
\hline S.No. & Characteristic & State & Clones & $\begin{array}{c}\text { Type of } \\
\text { assessment }\end{array}$ \\
\hline \multirow[t]{2}{*}{1.} & \multirow[t]{2}{*}{ Lenticel shape } & Oval & $\begin{array}{l}\text { CJ 19240-01, CJ 19240-02, CJ 19240-06, CJ 19553-07, CJ 19553- } \\
\text { og, CJ 19553-12 and CJ 19553-13 }\end{array}$ & \\
\hline & & Eye & $\begin{array}{c}\text { CJ 19240-03, CJ 19240-04, CJ 19240-05, CJ 19553-08, CJ 19553- } \\
\text { 10, CJ 19553-11, CJH-01-14, CJH-02, MTP2 (Check) and CJ } \\
\text { 19553 SS }\end{array}$ & VG \\
\hline \multirow[t]{3}{*}{2.} & \multirow[t]{3}{*}{ Lenticel: Size } & Small $(<0.5 \mathrm{~mm})$ & $\begin{array}{c}\text { CJ 19240-01,CJ 19240-02, CJ 19240-03,CJ 19240-04, CJ 19240- } \\
\text { 05,CJ 19240-06, CJ 19553-07,CJ 19553-08 } \\
\text { CJ 19553-09,CJ 19553-10, CJ 19553-11,CJ 19553-12, CJ 19553- } \\
\text { 13,CJH-01-14 } \\
\text { CJH-02,MTP2, CJ 19553 SS }\end{array}$ & \multirow{3}{*}{ VG } \\
\hline & & $\begin{array}{c}\text { Medium } \\
(0.5 \text { to } 1.5 \mathrm{~mm})\end{array}$ & - & \\
\hline & & $\begin{array}{c}\text { Large } \\
(>1.5 \mathrm{~mm})\end{array}$ & - & \\
\hline \multirow[t]{3}{*}{3.} & \multirow[t]{3}{*}{$\begin{array}{l}\text { Lenticels: } \\
\text { Grouping }\end{array}$} & Vertical & $\begin{array}{l}\text { CJ 19240-04, CJ 19240-06, CJ 19553-07, CJ 19553-09 and CJH- } \\
02\end{array}$ & \\
\hline & & Cluster & $\begin{array}{c}\text { CJ 19240-02, CJ 19553-08, CJ 19553-11, CJ 19553-12, CJ 19553- } \\
13 \text { and CJ 19553 SS }\end{array}$ & \\
\hline & & Mixed & $\begin{array}{l}\text { CJ 19240-01, CJ 19240-03,CJ 19240-05, CJ 19553-10,CJH-01-14, } \\
\text { MTP2 }\end{array}$ & VG \\
\hline \multirow[t]{3}{*}{4.} & \multirow[t]{3}{*}{$\begin{array}{l}\text { Lenticels: } \\
\text { Density }\end{array}$} & $\begin{array}{c}\text { Low } \\
\text { (21-30per sq. cm) }\end{array}$ & $\begin{array}{l}\text { CJ 19240-01, CJ 19240-02, CJ 19240-03, CJ 19240-05, CJ 19553- } \\
\text { 07, CJ 19553-08, CJ 19553-11, CJ 19553-12 and CJ 19553 SS }\end{array}$ & \\
\hline & & $\begin{array}{c}\text { Intermediate } \\
\text { (31-40per sq. cm) }\end{array}$ & CJ 19553-10, CJ 19553-13,CJH-01-14, MTP2 (Check) & \\
\hline & & $\begin{array}{c}\text { High } \\
\text { (41-50per sq. cm) }\end{array}$ & $\begin{array}{c}\text { CJ 19240-01, CJ 19240-02,CJ 19240-03, CJ 19240-05,CJ 19553- } \\
\text { 07, CJ 19553-08,CJ 19553-11, CJ 19553-12, } \\
\text { CJ 19553 SS }\end{array}$ & VG \\
\hline
\end{tabular}

\section{DUS traits for Lenticel}

Two types of lenticel shape are observed in casuarina clones which are oval and eye shaped. Seven clones viz., CJ 19240-01, CJ 19240-02,CJ 19240-06, CJ 19553-07, CJ 19553-09, CJ 19553-12 and CJ 19553-13 registered oval shape lenticels and the remaining 10 clones exhibited eye shaped lenticels [Table-2]. The lenticel size of all 17 clones was less than $0.5 \mathrm{~mm}$, so all clones are grouped into small category. Based on lenticels grouping, Five clones viz., CJ 19240-04, CJ 19240-06, CJ 19553-07, CJ 19553-09 and CJH-02 are grouped under vertical. The remaining twelve clones are grouped under cluster and mixed category
[Table-2]. Lenticel density of casuarina clones are grouped as low (21-30 per $\mathrm{cm}^{2}$ ), intermediate (31-40 per $\left.\mathrm{cm}^{2}\right)$ and high (41-50 per $\left.\mathrm{cm}^{2}\right)$. Nine clones viz., $\mathrm{CJ}$ 19240-01, CJ 19240-02, CJ 19240-03, CJ 19240-05, CJ 19553-07, CJ 19553-08, CJ 19553-11, CJ 19553-12 and CJ 19553 SS grouped under low density category. The remaining clones are grouped under intermediate and high lenticel density category [Table-2]. Such variations with references to lenticel shape, lenticel size and lenticel density may vary due to internal (hereditary) and external (environmental) factors [6].

\begin{tabular}{|c|c|c|c|c|}
\hline \multicolumn{5}{|c|}{ Table-3 DUS traits for branch } \\
\hline $\begin{array}{l}\text { S. } \\
\text { No. }\end{array}$ & Characteristic & State & Clones & $\begin{array}{c}\text { Type of } \\
\text { assessment }\end{array}$ \\
\hline 1. & Branching pattern & Single & $\begin{array}{l}\text { CJ 19240-01,CJ 19240-02 } \\
\text { CJ 19240-03,CJ 19240-04 } \\
\text { CJ 19240-05,CJ 19240-06 } \\
\text { CJ 19553-07,CJ 19553-08 } \\
\text { CJ 19553-09,CJ 19553-10 } \\
\text { CJ 19553-11,CJ 19553-12 } \\
\text { CJ 19553-13,CJH-01-14 } \\
\text { CJH-02,MTP2,CJ 19553 SS }\end{array}$ & \multirow[t]{2}{*}{ VS } \\
\hline & & Paired & - & \\
\hline \multirow[t]{2}{*}{2.} & \multirow[t]{2}{*}{ Branch angle } & Upward $\left(<60^{\circ}\right)$ & $\begin{array}{c}\text { CJ 19240-04, CJ 19240-06, CJ 19553-09, CJH- } \\
\text { 01-14, CJH-02 and MTP2 (Check) }\end{array}$ & \multirow[b]{2}{*}{ VS } \\
\hline & & Horizontal (60 to 900) & $\begin{array}{c}\text { CJ 19240-01,CJ 19240-02 } \\
\text { CJ 19240-03,CJ 19240-05, } \\
\text { CJ 19553-07,CJ 19553-08 } \\
\text {,CJ 19553-10,CJ 19553-11, CJ 19553-12,CJ } \\
\text { 19553-13, } \\
\text { CJ 19553 SS }\end{array}$ & \\
\hline \multirow[t]{3}{*}{3.} & \multirow[t]{3}{*}{ Branch: Thickness } & Thin $(<1.5 \mathrm{~cm})$ & CJ 19553-09 and MTP2 (Check) & \multirow{3}{*}{ VS } \\
\hline & & Medium $(1.5$ to $2.5 \mathrm{~cm})$ & $\begin{array}{c}\text { CJ 19240-01,CJ 19240-02 } \\
\text { CJ 19240-03,CJ 19240-04 } \\
\text { CJ 19240-05,CJ 19240-06 } \\
\text { CJ 19553-07,CJ 19553-08 } \\
\text { CJ 19553-10, CJ 19553-11, CJ 19553-12, CJ } \\
\text { 19553-13, CJH-01-14, CJH-02, } \\
\text { CJ 19553 SS } \\
\end{array}$ & \\
\hline & & Thick $(>2.5 \mathrm{~cm})$ & & \\
\hline
\end{tabular}




\section{DUS traits for Branching Pattern}

The branching Pattern of casuarina clones are categorized as single, paired and Cluster [Table-3]. All 17 casuarina clones expressed single branching pattern [Table-3]. The branch angle was categorized as upward $\left(<60^{\circ}\right)$ and horizontal $(60-$ 900). Six clones viz., CJ 19240-04, CJ 19240-06, CJ 19553-09, CJH-01-14, CJH02 and MTP2 expressed the upward branch angle and rest of the clones is grouped under horizontal branch angle. The branch thickness of the casuarina clones have been categorized as thin $(<1.5 \mathrm{~cm})$, medium $(1.5-2.5 \mathrm{~cm})$ and thick (>2.5). Two clones viz., CJ 19553-09 and MTP2 exhibited thin branches and all the other fifteen genetic resources exhibited the medium thickness of branches [Table-3]. [7] reported significant variation in branching pattern (Top, base and intermediate) of Jatropha curcus.

\begin{tabular}{|c|c|c|c|c|}
\hline S. No. & $\begin{array}{c}\text { Characteristi } \\
c\end{array}$ & State & Clones & $\begin{array}{c}\text { Type of } \\
\text { assessment }\end{array}$ \\
\hline \multirow[t]{3}{*}{1.} & \multirow[t]{3}{*}{ Bark colour } & Grey & $\begin{array}{l}\text { CJ 19240-02,CJ 19240-03, } \\
\text { CJ 19240-05,CJ 19553-07, } \\
\text { CJ 19553-08,CJ 19553-09, } \\
\text { CJ 19553-11,CJ 19553-12, } \\
\text { CJH-01-14,CJ 19553 SS }\end{array}$ & \multirow{3}{*}{ VS } \\
\hline & & Pinkish purple & CJ 19240-01 and CJH-02 & \\
\hline & & Brown & $\begin{array}{l}\text { CJ 19240-04, CJ 19240-06, CJ 19553-10, CJ 19553- } \\
13 \text { and MTP2 (Check) }\end{array}$ & \\
\hline \multirow[t]{2}{*}{2.} & \multirow[t]{2}{*}{ Bark texture } & Smooth & $\begin{array}{c}\text { CJ 19240-04, CJ 19240-06, } \\
\text { CJ 19553-09, CJ 19553-12, CJH-02 and MTP2 }\end{array}$ & \multirow[b]{2}{*}{ VS } \\
\hline & & Rough & $\begin{array}{c}\text { CJ 19240-01,CJ 19240-02 } \\
\text { CJ 19240-03,CJ 19240-05, } \\
\text { CJ 19553-07,CJ 19553-08, } \\
\text { CJ 19553-10,CJ 19553-11, } \\
\text { CJ 19553-13,CJH-01-14 CJ 19553 SS }\end{array}$ & \\
\hline \multirow[t]{2}{*}{3.} & \multirow[t]{2}{*}{ Crown shape } & Lanceolate & $\begin{array}{c}\text { CJ 19240-01,CJ 19240-02, } \\
\text { CJ 19240-03,CJ 19240-06, } \\
\text { CJ 19553-07,CJ 19553-08, } \\
\text { CJ 19553-09, CJ 19553-11, } \\
\text { CJ 19553-12,CJ 19553-13, } \\
\text { CJH-01-14,CJH-02, } \\
\text { CJ 19553 SS }\end{array}$ & \multirow{2}{*}{ VS } \\
\hline & & Conical & $\begin{array}{l}\text { CJ 19240-04, CJ 19240-05, CJ 19553-07, CJ 19553- } \\
10 \text { and MTP2 (Check) }\end{array}$ & \\
\hline
\end{tabular}

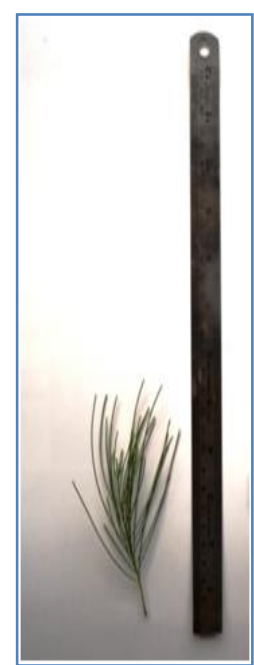

Short

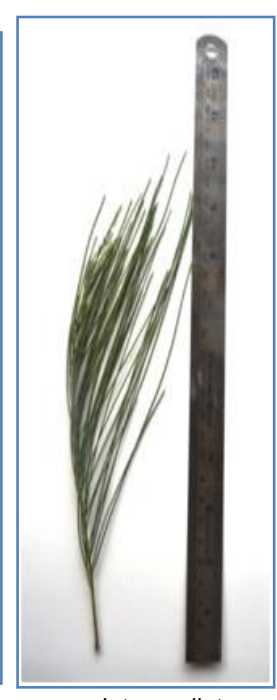

Intermediate

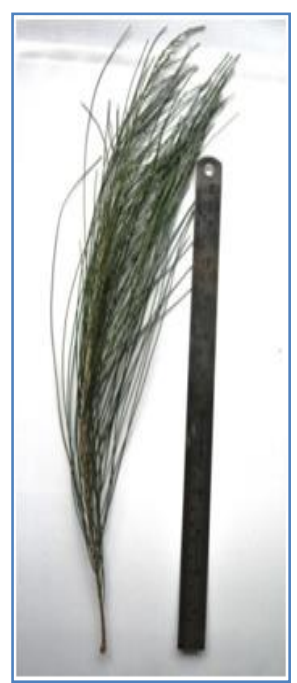

Long
Fig-1 Different type of branchlet character in Casuarina genetic resources

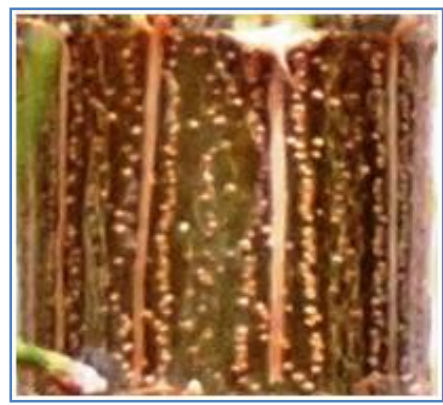

Oval shape

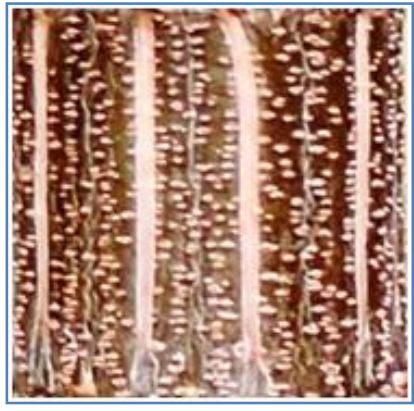

Eye shape
Fig-2 Different type of lenticel shape in Casuarina genetic resources

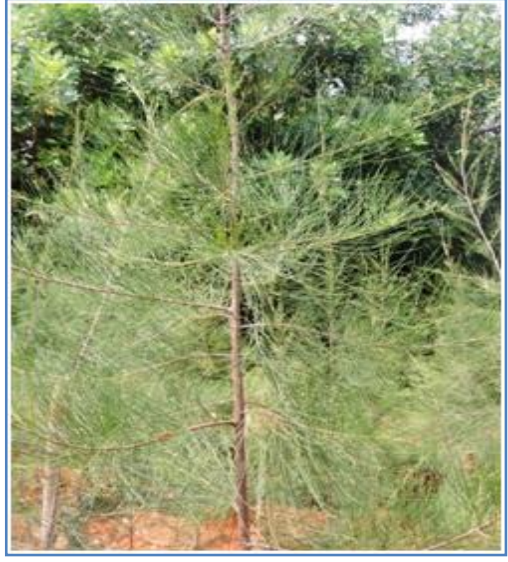

Horizontal branching pattern

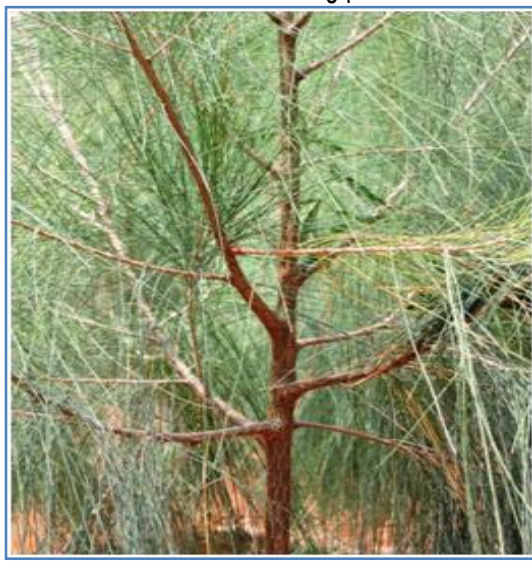

Upward branching pattern

Fig-3 Different type of branching pattern in Casuarina genetic resources 


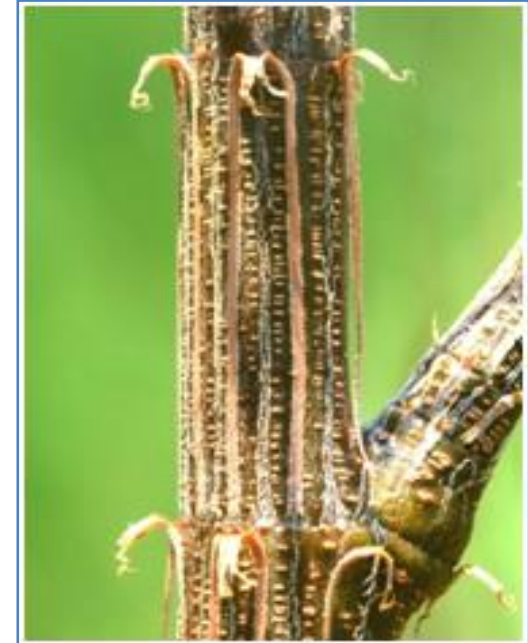

Brown



Pinkish purple

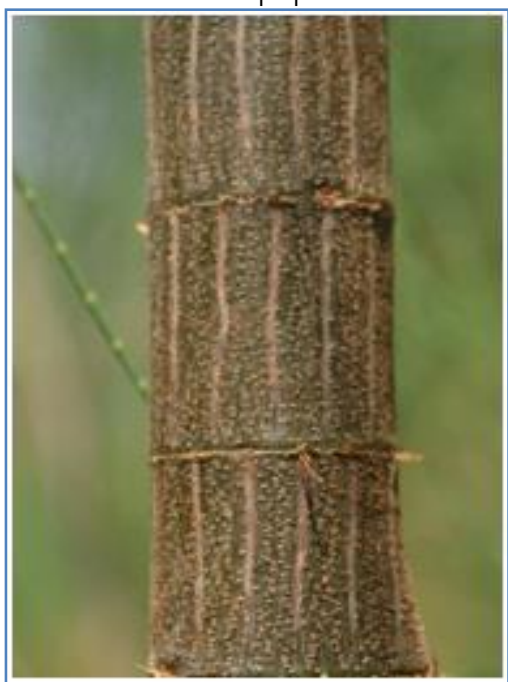

Grey

Fig-4 Different type of bark color in Casuarina genetic resources

\section{DUS traits for Bark Characters}

The bark Texture of Casuarina Clones Are grouped into two categories viz., smooth and rough [Table-4]. Six clones viz., CJ 19240-04, CJ 19240-06, CJ 19553-09, CJ 19553-12, CJH-02 and MTP2 exhibited the smooth bark and the remaining eleven clones exhibited rough bark texture. Similarly, the Casuarina Clones Exhibited Three Different Types of Bark Colour Viz., Grey, Pinkish Purple and Brown. Two clones viz., CJ 19240-01 and CJH-02 expressed pinkish purple bark colour. The remaining 15 clones expressed the grey and brown coloured bark indicating the presence of significant variability in bark colour. A similar study was carried in Cedrus deoder, where as they categorized bark colour as Grey, Dark grey, Grayish brown, Reddish brown, Brown (PPV\&FRA 2014).

\section{Conclusion}

The descriptor was developed and documented for Casuarina genetic resources. Characterization of clones through morphological traits is the simplest, quickest and easily adoptable method for identification of clones at the field level which is mandatory for tree improvement programmes. These descriptors would also be helpful to identify and protect the casuarina genetic resource. Beside this, in emerging need of intellectual property rights (IPR) regimes, this investigation would also facilitate as baseline DUS data for varietal registration of casuarina clones under Protection of Plant Varieties and Farmer's Rights (PPV\&FR) Authority.

\section{Application of research}

The result gives specific information about various genetic resources with their morphological characteristics, this helps farmers to identify their genetic resource and they can register under Protection of Plant Variety and Farmers Right Act.

Acknowledgment: This is a part of scheme "Development of high yielding short rotation clones for Industrial Agroforestry" Financially assisted By Indian Council of Agricultural Research (ICAR) for the great full Acknowledged

Research Category: Genetic diversity, Plant breeding

\author{
*Abbreviations: \\ DUS- Distinctiveness, Uniformity, Stability \\ RBD - Randomized block design \\ PPV and FRA- Protection of Plant Variety and Farmers Right Act \\ IPR - Intellectual property rights \\ ICAR - Indian council of agricultural Research
}

\section{*Principle Investigator: Dr K.T. Parthiban}

University: Tamil Nadu Agricultural University, Coimbatore, Tamil Nadu 641003 India

Research project name: ICAR- Development of High Yielding Short Rotation (HYSR) clones for Industrial Agroforestry.

Author Contributions: All authors have contributed substantially in conception, designing of the study, acquisition of data, analysis and interp retation of data.

Author statement: All authors read, reviewed, agree and approved the final manuscript

Conflict of Interest: None declared

\section{References}

[1] Pan Y., Li Y. and Tan T.Y. (1996) For. Res., 9, 138-145.

[2] Yasodha R., Kathirvel M., Sumathi R., Gurumurthi K. (2004) Genetica., 122, 161-172.

[3] PPV\&FRA (2006) Proceedings of the First Meeting of the Protection of Plant Varieties and Farmers' Rights (PPV\&FR) Authority held on 18th May 2006 in the Committee Room of PPV\&FR Authority, under the Chairmanship of Chairperson of PPV\&FR Authority.

[4] UPOV (1989) Guidelines for the conduct of tests for distinctness, homogeneity and stability. Banana (Musa acuminate Colla).TG/123/3. International Union for the Protection of New Varieties and Plants (UPOV), Geneva. 26 p.

[5] Gnanasekar S. and Balasubramanian A. (2014) Indian Journal of Animal Nutrition, 7(16). 
[6] Nicodemus A., Rekha R. Warrier, Sivakumar V., Anandalakshmi R., Pauldasan A. and Gurudev Singh B. (2012) Descriptors and DUS Testing Guidelines for Casuarinas, Fifth International Casuarina Workshop, Mamallapuram, Chennai, India, 03-07 February 2014.

[7] George A.K., Parthiban K.T. and Vikas Kumar (2016) Indian J Trop Biodiv., 24(1). 